\title{
Pengaruh Terapi Dzikir Tasbih Pada Pasien Pre Operasi Bedah Hernioraphy Terhadap Tekanan Darah Di Ruang Rawat Inap RSUD Kota Semarang
}

\author{
Achmad Syaifudin ${ }^{1}$, Anwar Adi Purwanto ${ }^{2}$, \\ 1. STIKES Karya Husada Semarang \\ 2. STIKES Karya Husada Semarang \\ E-mail:udin_gantheng@yahoo.com
}

\begin{abstract}
Abstrak
Berdasarkan survei pendahuluan jumlah kasus hernioraphy pada tahun 2014 sebanyak 135 kasus. Pada tahun 2015 mengalami peningkatan menjadi 145 kasus. Untuk mengetahui pengaruh terapi dzikir tasbih pada pasien pre operasi bedah hernioraphy terhadap tekanan darah. Jenis penelitian yang digunakan adalah eksperimental semu (quasi experiment). Desain penelitian ini adalah static group comparison. Populasi dalam penelitian ini adalah pasien hernioraphy pada bulan Januari dan Februari 2016 sebanyak 25 kasus. Sampel penelitian kelompok perlakuan sebanyak 15 orang dan kelompok kontrol sebanyak 15 orang. Teknik pengambilan sampel pada penelitian ini adalah purposive sampling. Ada perbedaan tekanan darah sistole pada kelompok perlakuan. Ada perbedaan tekanan darah diastole pada kelompok perlakuan. Ada perbedaan tekanan darah sistole pada kelompok kontrol. Ada perbedaan tekanan darah diastole pada kelompok kontrol. Ada perbedaan yang signifikan terapi dzikir tasbih pada pasien pre operasi bedah hernioraphy terhadap tekanan darah sistole di Ruang Rawat Inap RSUD Kota Semarang. Ada perbedaan yang signifikan terapi dzikir tasbih pada pasien pre operasi bedah hernioraphy terhadap tekanan darah diastole. Rumah sakit sebaiknya menerapkam terapi non farmakologi seperti terapi dzikir untuk mengatasi peningkatan tekanan darah pada pasien yang akan menjalani operasi agar pasien merasa tenang dan tidak cemas saat akan operasi.
\end{abstract}

Kata Kunci: Pasien pre operasi bedah hernioraphy; tekanan darah; terapi dzikir tasbih

\section{The Effect Of Therapy In Patients Pre Dhikr Tasbih Hernioraphy Surgery Operation Of Pressure Inpatient At Semarang Hospital}

\begin{abstract}
Based on the preliminary survey the number of cases hernioraphy in 2014 as many as 135 cases. In 2015 increased to 145 cases. To determine the effect of therapy in patients with pre dhikr beads hernioraphy surgery on blood pressure. This type of research is a quasi-experimental (quasi experiment). This study design is a static group comparison. The population in this study were patients hernioraphy in January and February 2016 as many as 25 cases. The research sample treatment group of 15 people and a control group of 15 people. The sampling technique in this research is purposive sampling. There are differences in systolic blood pressure in the treatment group. There is a difference in diastolic blood pressure in the treatment group. There are differences in systolic blood pressure in the control group. There is a difference in diastolic blood pressure in the control group. There are significant differences dhikr beads therapy in patients with pre surgery hernioraphy the systolic blood pressure. There are significant differences dhikr beads therapy in patients with pre surgery hernioraphy the diastolic blood pressure. Hospitals should menerapkam non-pharmacological therapies such as dhikr therapy to cope with an increase in blood pressure in patients who will undergo surgery so that the patient feel calm and not anxious when going operations.
\end{abstract}

Keywords: Dhikr Tasbih therapy; the patient's pre hernioraphy surgery; blood pressure

Jurnal SMART Keperawatan Sekolah Tinggi Ilmu Kesehatan (STIKes) Karya Husada Semarang www.stikesyahoedsmg.ac.id/ojs/index.php/sjkp(perawat) 


\section{Pendahuluan}

Dewasa ini di zaman modern dengan adanya peningkatan derajat ekonomi yang juga terjadi pada masyarakat sangat berpengaruh terhadap gaya hidup sehari-hari, misalnya pola aktifitas dan pekerjaan, namun tanpa disadari bahaya yang mengancam kesehatan juga tidak dapat dihindari, dan hernia merupakan masalah kesehatan yang sering muncul karena hal tersebut (Sjamsuhidajat \& Jong, 2010).

Hernia merupakan suatu penonjolan isi perut dari rongga yang normal melalui suatu defek pada fasia dan muskuloaponeuretik dinding perut, secara kongenital yang memberi jalan keluar pada setiap alat tubuh selain yang biasa melalui dinding tersebut. Lubang itu dapat timbul karena lubang embrional yang tidak menutup atau melebar, akibat tekanan rongga perut yang meninggi (Mansjoer, 2010).

Angka kejadian hernia inguinalis (medialis / direk dan lateralis / indirek) 10 kali lebih banyak dari pada hernia femoralis dan keduanya mempunyai persentase sekitar 75-80\% dari seluruh jenis hernia, hernia insisional 10\%, hernia ventralis $10 \%$, hernia umbilikalis $3 \%$, dan hernia lainnya sekitar 3\% (WHO, 2015).

Secara umum, kejadian hernia inguinalis lebih banyak diderita oleh laki-laki dari pada perempuan. Angka perbandingan kejadian hernia inguinalis 13,9\% pada laki-laki dan 2,1\% pada perempuan. Setiap tahun diperkirakan terdapat 20 juta kasus prosedur bedah mengenai hernia inguinalis. Tingkat prosedur operasi dalam berbagai negara memiliki tingkat yang bervariasi, berkisar antara 100 hingga 300 prosedur per 100.000 orang dalam satu tahun. Kasus hernia inguinalis di Amerika Serikat sekitar 800.000 kasus setiap tahun dan negara Belanda sekitar 33.000 kasus setiap tahun. Di Indonesia hernia menempati urutan kedelapan dengan jumlah 292.145 kasus (Profil Kesehatan Indonesia, 2015).

Operasi atau pembedahan merupakan salah satu tindakan atau terapi medis yang menggunakan tindakan invasif dengan membuka bagian tubuh yang akan ditangani. Pembedahan merupakan suatu tindakan pengobatan yang menggunakan cara invasif dengan membuka dan menangani bagian tubuh yang akan dilakukan pembedahan. Pembukaan bagian tubuh ini umumnya dilakukan dengan membuat sayatan setelah bagian yang akan ditangani ditampilkan, dilakukan tindakan perbaikan yang diakhiri dengan penutupan dan penjahitan luka (Sjamsuhidayat \& Jong, 2010). 
Operasi yang akan dilakukan membutuhkan persiapan mental dan bergantung pada keperawatan preoperative yang merupakan tahapan awal dari keperawatan preoperative. Kesuksesan tindakan operasi secara keseluruhan sangat bergantung pada fase ini. Hal ini disebabkan fase ini merupakan landasan awal untuk kesuksesan tahapan-tahapan berikutnya. Kesalahan yang dilakukan pada tahap ini akan berakibat fatal pada tahap berikutnya (Rothrock, 2012).

Faktor-faktor yang mempengaruhi fisiologi tekanan darah diantaranya yaitu pengembalian darah melalui vena, frekuensi dan kekuatan kontraksi jantung, resistensi perifer, elastisits arteri besar, viskositas darah, kehilangan darah dan hormon (Muttaqin, 2010). Tekanan darah juga ditentukan oleh banyak faktor, diantaranya : Jantung, denyut jantung, volume darah, sistem saraf, sistem hormon, sistem metabolik, pikiran atau stres. Di Amerika hampir 70\% masyarakatnya memiliki tekanan darah yang tidak terkontrol. Sejauh ini pemberian obat-obatan, olah raga, diet rendah garam, olah raga secara teratur, ternyata masih belum mampu mengontrol tekanan darah (Udjianti, 2010).

Cara meminimalkan perubahan tekanan darah ini, dapat dilakukan dengan farmakologi dan non farmakologi. Cara non farmakologi, yaitu dengan melakukan latihan meditasi dengan relaksasi yang akan menurunkan ketegangan psikis. Berbagai cara untuk mendapatkan keadaan relaksasi diantaranya seperti meditasi, yoga, hypnosis (hipnotis), spiritual (dzikir) dan terapi musik yang dikatakan dapat mengontrol sistem saraf autonom sehingga dapat menurunkan tekanan darah (Devi, 2010).

Word Health Organization (WHO) telah menetapkan unsur spiritual (agama) sebagai salah satu dari 4 unsur kesehatan. Keempat unsur kesehatan tersebut adalah sehat fisik, sehat psikis, sehat sosial dan sehat spiritual. Doa yang berarti seruan, menyampaikan ungkapan, permintaan, permohonan pertolongan adalah menghadapnya seseorang dengan tulus ikhlas kepada Allah, dan memohon pertolongan dari-Nya, Yang Maha Kuasa, Maha Pengasih dan Penyayang (Elkaysi, 2012).

Dipandang dari sudut kesehatan jiwa, doa dan dzikir mengandung unsur psikoterapeutik yang mendalam. Terapi psikoreligius tidak kalah pentingnya dibandingkan dengan psikoterapi psikiatrik, karena ia mengandung kekuatan spiritual atau kerohanian yang membangkitkan rasa percaya diri dan rasa optimisme. Dua hal ini, yaitu rasa percaya diri (self confident) dan optimisme merupakan dua hal yang amat esensial bagi penyembuhan suatu penyakit disamping 
obat-obatan dan tindakan medis lainnya (Hawari, 2012).

Penelitian Nafi'ah (2015), hasil penelitian terdapat perbedaan tekanan darah sistol dan diastol pasien pasca operasi dengan anestesi umum antara kelompok murottal Al-Quran dengan kelompok tanpa murottal Al-Quran dan tidak terdapat perbedaan frekuensi denyut jantung pasien pasca operasi dengan anestesi umum antara kelompok murottal Al-Quran dengan kelompok tanpa murottal Al-Quran. Didukung penelitian Suherly (2011), hasil penelitian menunjukkan bahwa ada perbedaan tekanan darah pasien hipertensi sebelum dan sesudah terapi musik.

Berdasarkan fenomena-fenomena diatas, peneliti tertarik untuk melakukan penelitian tentang: "Pengaruh terapi dzikir tasbih pada pasien pre operasi bedah hernioraphy terhadap tekanan darah di Ruang Rawat Inap RSUD Kota Semarang”..

\section{Tinjauan Teoritis Metode Penelitian}

Tekanan darah yaitu tekanan yang dialami darah pada pembuluh arteri ketika darah dipompa oleh jantung ke seluruh anggota tubuh manusia. Tekanan darah dibuat dengan mengambil dua ukuran dan biasanya terdapat dalam angka yang akan muncul. Tekanan darah sistole adalah tekanan yang terjadi ketika otot jantung berdenyut memompa darah sehingga darah terdorong keluar dari jantung menuju ke seluruh tubuh (kontraksi). Tekanan darah diastolik merupakan kebalikan dari tekanan sistolik yaitu tekanan darah saat darah memasuki jantung (istirahat) (Perry \& Potter, 2010).

Menurut Assidiqi (2012) dzikir adalah menyebut nama Allah SWT, dengan membaca tasbih (subhanallah), tahlil (la ilaha illahu), tahmid (Alhamdu), basmallah (bismillahirahmanirrahim) dan membaca al-Qur'an serta membaca do'a-do'a yang diterima dari Nabi Muhammad SAW.

Bedah mayor adalah istilah yang dipakai untuk tindakan operasi besar yang biasanya dikerjakan dengan anastesi umum/general anesthesy (Mansjoer, 2010). Bedah mayor adalah tindakan bedah yang dilakukan dalam rangka tindakan pengobatan terhadap adanya kelainankelainan pada organ tubuh (Smeltzer \& Bare, 2010).

Menurut Mansjoer (2010) menyatakan, hernia merupakan suatu penonjolan isi perut dari rongga yang normal melalui lubang kongenital atau didapat. Menurut Syamsuhidajat dan Jong (2010), hernia merupakan produksi atau penonjolan isi suatu rongga melalui defek atau bagian lemah dari dinding rongga bersangkutan. 


\section{Metode Penelitian}

Jenis penelitian yang digunakan adalah eksperimental semu (quasi experiment). Desain penelitian ini adalah static group comparison. Pelaksanaan penelitian ini dimulai dari bulan April 2016 sampai dengan bulan Desember 2016. Penelitian dilakukan di ruang rawat inap RSUD Kota Semarang. Populasi dalam penelitian ini adalah pasien hernioraphy ruang rawat inap RSUD Kota Semarang pada bulan Januari dan Februari 2016 sebanyak 25 kasus. Sampel penelitian ini dibagi menjadi dua kelompok. Kelompok perlakuan sebanyak 15 orang dan kelompok kontrol sebanyak 15 orang. Teknik pengambilan sampel pada penelitian ini adalah purposive sampling.

Setelah dilakukan pengumpulan data kemudian data dianalisa menggunakan statistik deskriptif untuk mendapatkan dalam bentuk tendensi sentral berupa : mean, minimum, maksimum dan standar deviasi dari masing-masing item yaitu tekanan darah sistole dan diastole sebelum dan sesudah diberikan terapi dzikir tasbih, kelompok kontrol juga dilakukan pengukuran tekanan darah sistole dan diastole sebelum dan sesudah. Untuk mengetahui perbedaan tekanan darah sistole dan diastole pada kelompok perlakuan dan perbedaan tekanan darah sistole dan diastole pada kelompok kontrol menggunakan uji Wilcoxon. Sedangkan untuk mengetahui pengaruh terapi dzikir tasbih pada pasien pre operasi bedah hernioraphy terhadap tekanan darah sistole dan diastole menggunakan uji Mann Whitney.

\section{Hasil Penelitian}

Tekanan darah sistole dan diastole sebelum terapi kelompok perlakuan pada pasien pre operasi bedah hernioraphy

Tabel 1 Distribusi responden berdasarkan tekanan darah sistole dan diastole sebelum terapi kelompok perlakuan pada pasien pre operasi bedah hernioraphy

\begin{tabular}{lcccccc}
\hline Variabel & & n & Mean & SD & Min & Max \\
\hline $\begin{array}{l}\text { Tekanan darah sistole sebelum terapi terapi } \\
\text { kelompok perlakuan }\end{array}$ & 15 & 150 & 10,69 & 130 & 170 \\
\hline & & & & & \\
\hline $\begin{array}{l}\text { Tekanan darah diastole sebelum terapi kelompok } \\
\text { perlakuan }\end{array}$ & 15 & 88 & 5,60 & 80 & 100 \\
\hline
\end{tabular}


Tekanan darah sistole dan diastole sebelum kelompok kontrol pada pasien pre operasi bedah hernioraphy

Tabel 2 Distribusi responden berdasarkan tekanan darah sistole dan diastole sebelum kelompok kontrol pada pasien pre operasi bedah hernioraphy

\begin{tabular}{lllllll}
\hline \multicolumn{1}{c}{ Variabel } & n & Mean & SD & Min & Max \\
\hline Tekanan darah sistole sebelum kelompok kontrol & 15 & 151,33 & 11,25 & 140 & 170 \\
\hline & & & & & & \\
\hline $\begin{array}{l}\text { Tekanan darah diastole sebelum kelompok } \\
\text { kontrol }\end{array}$ & 15 & 86,67 & 8,99 & 70 & 100 \\
\hline
\end{tabular}

Tekanan darah sistole dan diastole sesudah terapi kelompok perlakuan pada pasien pre operasi bedah hernioraphy

Tabel 3 Distribusi responden berdasarkan tekanan darah sistole sesudah terapi kelompok perlakuan pada pasien pre operasi bedah hernioraphy

\begin{tabular}{llllll}
\hline \multicolumn{1}{c}{ Variabel } & n & Mean & SD & Min & Max \\
\hline $\begin{array}{l}\text { Tekanan darah sistole sesudah terapi kelompok } \\
\text { perlakuan }\end{array}$ & 15 & 135,33 & 9,15 & 120 & 150 \\
\hline & & & & & \\
\hline $\begin{array}{l}\text { Tekanan darah diastole sesudah terapi kelompok } \\
\text { perlakuan }\end{array}$ & 15 & 76 & 5,07 & 70 & 80 \\
\hline
\end{tabular}

Tekanan darah sistole dan diastole sesudah kelompok kontrol pada pasien pre operasi bedah hernioraphy

Tabel 4 Distribusi responden berdasarkan tekanan darah sistole dan diastole sesudah kelompok kontrol pada pasien pre operasi bedah hernioraphy di Ruang Rawat Inap RSUD Kota Semarang

\begin{tabular}{cccccc}
\hline Variabel & $\mathrm{n}$ & Mean & SD & Min & Max \\
\hline Tekanan darah sistole sesudah kelompok kontrol & 15 & 144 & 5,07 & 140 & 150 \\
\hline
\end{tabular}




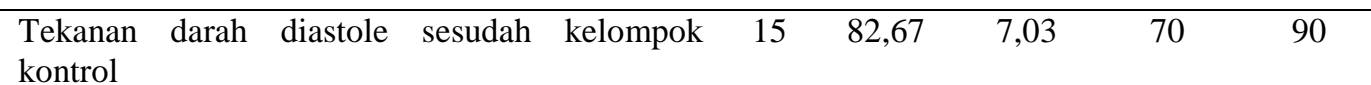

Perbedaan tekanan darah sistole dan diastole pada kelompok perlakuan

Tabel 5 Perbedaan tekanan darah sistole dan diastole pada kelompok perlakuan di Ruang Rawat Inap RSUD Kota Semarang

\begin{tabular}{lccc}
\hline \multicolumn{1}{c}{ Kelompok Perlakuan } & Mean & SD & P-value \\
\hline $\begin{array}{l}\text { Tekanan darah sistole sebelum pada kelompok perlakuan } \\
\text { Tekanan darah sistole sesudah pada kelompok perlakuan }\end{array}$ & 150 & 10,69 \\
& 135,33 & 9,15 & 0,000 \\
& & \\
\hline Tekanan darah diastole sebelum pada kelompok perlakuan & 88 & 5,60 \\
Tekanan darah diastole sesudah pada kelompok perlakuan & 76 & 5,07 & 0,000
\end{tabular}

Perbedaan tekanan darah sistole dan diastole pada kelompok kontrol

Tabel 6 Perbedaan tekanan darah sistole pada kelompok kontrol di Ruang Rawat Inap RSUD Kota Semarang

\begin{tabular}{lccc}
\hline Variabel & Mean & SD & P-value \\
\hline Tekanan darah sistole sebelum pada kelompok kontrol & 151,33 & 11,25 \\
Tekanan darah sistole sesudah pada kelompok kontrol & 144 & 5,07 & 0,038 \\
\hline Tekanan darah diastole sebelum pada kelompok kontrol & 86,67 & 8,99 & 0,014 \\
\hline Tekanan darah diastole sesudah pada kelompok kontrol & 82,67 & 7,03 & \\
\hline
\end{tabular}

Pengaruh terapi dzikir tasbih pada pasien pre operasi bedah hernioraphy terhadap tekanan darah sistole dan diastole

Tabel 7 Pengaruh terapi dzikir tasbih pada pasien pre operasi bedah hernioraphy terhadap tekanan darah sistole dan diastole di Ruang Rawat Inap RSUD Kota Semarang

$\begin{array}{llll}\text { Variabel } & \text { Mean } & \text { SD } & \text { Pvalue }\end{array}$




\begin{tabular}{llccr}
\hline $\begin{array}{l}\text { Tekanan darah sistole sesudah terapi kelompok perlakuan } \\
\text { Tekanan darah sistole sesudah kelompok kontrol }\end{array}$ & 135,33 & 9,15 & \\
& & 144 & 5,07 & 0,010 \\
\hline & & & & \\
\hline $\begin{array}{l}\text { Tekanan darah diastole sesudah terapi kelompok } \\
\text { perlakuan } \\
\text { Tekanan darah diastole sesudah kelompok kontrol }\end{array}$ & 86,67 & 7,03 & 0,016 \\
\hline
\end{tabular}

\section{Pembahasan}

\section{Tekanan darah sistole dan diastole sebelum terapi kelompok perlakuan pada pasien pre operasi bedah hernioraphy}

Hasil penelitian dapat diketahui tekanan darah sistole sebelum terapi kelompok perlakuan rata-rata $150 \mathrm{mmHg}$ dengan standar deviasi 10,69. Tekanan darah sistole sebelum terapi kelompok perlakuan paling rendah adalah $130 \mathrm{mmHg}$ dan tertinggi adalah $170 \mathrm{mmHg}$. Tekanan darah diastole sebelum terapi kelompok perlakuan rata-rata $88 \mathrm{mmHg}$ dengan standar deviasi 5,60 . Tekanan darah diastole sebelum terapi kelompok perlakuan paling rendah adalah $80 \mathrm{mmHg}$ dan tertinggi adalah $100 \mathrm{mmHg}$. Penelitian menunjukkan rata-rata tekanan darah sistole dan diastole yang tinggi. Hal ini dikarenakan operasi menimbulkan kecemasan yang dapat meningkatkan hormon norepinefrin dan epinefrin.

Pada saat stres, medula kelenjar adrenal akan menyekresikan norepinefrin dan epinefrin, yang keduanya akan menyebabkan vasokonstriksi sehingga meningkatkan tekanan darah. Selain dari vasokonstriksi, epinefrin juga berfungsi meningkatkan heart rate dan gaya kontraksi. Hormon lain yang berperan adalah ADH yang disekresikan oleh kelenjar hipofisis posterior saat tubuh mengalami kekurangan cairan. ADH akan meningkatkan reabsorpsi cairan pada ginjal sehingga tekanan darah tidak akan semakin turun. Hormon lain, aldosteron, memiliki efek serupa pada ginjal, dimana aldosteron akan mempromosikan reabsorpsi $\mathrm{Na}+$, lalu air akan mengikuti ion $\mathrm{Na}+$ ke darah (Udjianti, 2010).

Hasil penleitian ini didukung oleh penelitian Prasojo (2008) menunjukkan rata-rata tekanan darah sistolik sebelum operasi pada prostatektomi terbuka sebesar $153 \mathrm{mmHg}$, dan diastolik sebesar $90 \mathrm{mmHg}$. Rata-rata tekanan darah sistolik setelah operasi pada prostatektomi terbuka sebesar $129 \mathrm{mmHg}$, dan diastolik sebesar $79 \mathrm{mmHg}$. 
Hasil penelitian dapat diketahui bahwa tekanan darah sistole sebelum kelompok kontrol rata-rata 151,33 $\mathrm{mmHg}$ dengan standar deviasi 11,25. Tekanan darah sistole sebelum kelompok kontrol paling rendah adalah $140 \mathrm{mmHg}$ dan tertinggi adalah $170 \mathrm{mmHg}$. tekanan darah diastole sebelum kelompok kontrol rata-rata $86,67 \mathrm{mmHg}$ dengan standar deviasi 8,99. Tekanan darah diastole sebelum kelompok kontrol paling rendah adalah $70 \mathrm{mmHg}$ dan tertinggi adalah 100 mmHg. Hasil penelitian pada kelompok kontrol juga mengalami peningkatan tekanan darah sebelum dilakukan tindakan operasi.

Responden sebelum dilakukan operasi mengalami peningkatan tekanan darah karena mengalami kecemasan sebelum dilakukan operasi. Operasi atau pembedahan merupakan salah satu tindakan atau terapi medis yang menggunakan tindakan invasif dengan membuka bagian tubuh yang akan ditangani. Pembedahan merupakan suatu tindakan pengobatan yang menggunakan cara invasif dengan membuka dan menangani bagian tubuh yang akan dilakukan pembedahan. Pembukaan bagian tubuh ini umumnya dilakukan dengan membuat sayatan setelah bagian yang akan ditangani ditampilkan, dilakukan tindakan perbaikan yang diakhiri dengan penutupan dan penjahitan luka (Sjamsuhidayat \& Jong, 2010).

\section{Tekanan darah sistole dan diastole sesudah terapi kelompok perlakuan dan kelompok kontrol pada pasien pre operasi bedah hernioraphy}

Hasil penelitian dapat diketahui bahwa tekanan darah sistole sesudah terapi kelompok perlakuan rata-rata $135,33 \mathrm{mmHg}$ dengan standar deviasi 9,15 . Tekanan darah sistole sesudah terapi kelompok perlakuan paling rendah adalah $120 \mathrm{mmHg}$ dan tertinggi adalah $150 \mathrm{mmHg}$. Tekanan darah diastole sesudah terapi kelompok perlakuan rata-rata $76 \mathrm{mmHg}$ dengan standar deviasi 5,07. Tekanan darah diastole sesudah terapi kelompok perlakuan paling rendah adalah 70 $\mathrm{mmHg}$ dan tertinggi adalah $80 \mathrm{mmHg}$. Hasil penenelitian menunjukkan penurunan tekanan darah setelah diberikan terapi dixikir tasbih.

Dalam agama Islam, bagi mereka yang sakit dianjurkan untuk berobat kepada ahlinya (memperoleh terapi medis) disertai dengan berdoa dan berdzikir. Bagi pemeluk agama Islam, doa dan dzikir merupakan salah satu bentuk komitmen keagamaan / keimanan seseorang. Doa adalah permohonan yang dimunajatkan kehadirat Allah SWT, Tuhan Yang Maha Kuasa, Maha Pengasih, Maha Penyayang dan Maha Pengampun. Dzikir adalah mengingat Allah SWT dengan segala sifat-sifat-Nya. Dengan demikian yang dimaksudkan dengan "Doa dan Dzikir" adalah suatu amalan dalam bentuk kata-kata yang diucapkan secara lisan ataupun dalam hati yang 
berisikan permohonan kepada Allah SWT dengan selalu mengingat nama-Nya dan sifat-Nya (Gusmian, 2010).

Penelitian Nafi'ah (2015) hasil penelitian terdapat perbedaan tekanan darah sistol dan diastol pasien pasca operasi dengan anestesi umum antara kelompok murottal Al-Quran dengan kelompok tanpa murottal Al-Quran dan tidak terdapat perbedaan frekuensi denyut jantung pasien pasca operasi dengan anestesi umum antara kelompok murottal Al-Quran dengan kelompok tanpa murottal Al-Quran.

Hasil penelitian dapat diketahui bahwa tekanan darah sistole sesudah kelompok kontrol rata-rata $144 \mathrm{mmHg}$ dengan standar deviasi 5,07. Tekanan darah sistole sesudah kelompok kontrol paling rendah adalah $140 \mathrm{mmHg}$ dan tertinggi adalah $150 \mathrm{mmHg}$. Tekanan darah diastole sesudah kelompok kontrol rata-rata $82,67 \mathrm{mmHg}$ dengan standar deviasi 7,03. Tekanan darah diastole sesudah kelompok kontrol paling rendah adalah $70 \mathrm{mmHg}$ dan tertinggi adalah 90 $\mathrm{mmHg}$.

Tekanan darah sistole dan diastole yang tinggi dikarenakan kecemasan pada pasien preoperative. Pasien merasa takut terhadap nyeri atau kematian, takut tentang ketidaktahuan atau takut tentang deformitas atau ancaman lain terhadap citra tubuh. Selain itu pasien juga sering mengalami kecemasan lain seperti masalah finansial, tanggung jawab terhadap keluarga dan kewajiban pekerjaan atau ketakutan akan prognosa yang buruk dan probabilitas kecacatan di masa datang. Kecemasan pada pasien preoperasi menyebabkan tekanan darah menjadi naik ketika pasien akan menjalani operasi (Smeltzer \& Bare, 2010).

Hasil penelitian ini didukung oleh penelitian Suherly (2011) menunjukan tekanan sistole sebelum intervensi terapi musik pada pasien hipertensi di RSUD Tugurejo Semarang menunjukkan sebanyak 20 responden $(71,4 \%)$ mengalami hipertensi tingkat I.

\section{Perbedaan tekanan darah sistole dan diastole pada kelompok perlakuan}

Hasil penelitian dapat diketahui bahwa P-value $=0,000$, hal ini menunjukkan bahwa ada perbedaan tekanan darah sistole pada kelompok perlakuan di Ruang Rawat Inap RSUD Kota Semarang. Hasil penelitian dapat diketahui bahwa P-value $=0,000$, hal ini menunjukkan bahwa ada perbedaan tekanan darah diastole pada kelompok perlakuan di Ruang Rawat Inap RSUD Kota Semarang.

Hasil penelitian menunjukkan perbedaan tekanan darah sebelum dan sesudah diberikan terapi dzikir. Terapi dzikir memiliki aspek yang sangat diperlukan dalam mengatasi 
kecemasan, yakni kemampuanya dalam membentuk koping baru untuk mengatasi kecemasan sebelum operasi. Terapi dzikir secara psikologis dapat memotivasi dan memberikan dorongan semangat dalam menghadapi problem yang sedang dihadapi.

Dipandang dari sudut kesehatan jiwa, doa dan dzikir mengandung unsur psikoterapeutik yang mendalam. Terapi psikoreligius tidak kalah pentingnya dibandingkan dengan psikoterapi psikiatrik, karena ia mengandung kekuatan spiritual atau kerohanian yang membangkitkan rasa percaya diri dan rasa optimisme. Dua hal ini, yaitu rasa percaya diri (self confident) dan optimisme merupakan dua hal yang amat esensial bagi penyembuhan suatu penyakit disamping obat-obatan dan tindakan medis lainnya (Hawari, 2012).

Hasil penelitian Nafiah (2015) menunjukkan ada perbedaan tekanan darah sistol dan diastol pasien pasca operasi dengan anestesi umum antara kelompok murottal Al-Quran dengan kelompok tanpa murottal Al-Quran.

\section{Perbedaan tekanan darah sistole dan diastole pada kelompok kontrol}

Hasil penelitian dapat diketahui bahwa $\mathrm{P}$-value $=0,038$, hal ini menunjukkan bahwa ada perbedaan tekanan darah sistole pada kelompok kontrol di Ruang Rawat Inap RSUD Kota Semarang. Hasil penelitian dapat diketahui bahwa P-value $=0,014$, hal ini menunjukkan bahwa ada perbedaan tekanan darah diastole pada kelompok kontrol di Ruang Rawat Inap RSUD Kota Semarang.

Hasil penelitian menunjukkan ada perbedaan tekanan darah sistole dan diastole pada kelompok kontrol. Hal ini dikarenakan responden yang mampu menghadapi operasi dengan baik. Faktor-faktor yang mempengaruhi fisiologi tekanan darah diantaranya yaitu pengembalian darah melalui vena, frekuensi dan kekuatan kontraksi jantung, resistensi perifer, elastisits arteri besar, viskositas darah, kehilangan darah dan hormon (Muttaqin, 2010). Tekanan darah juga ditentukan oleh banyak faktor, diantaranya : Jantung, denyut jantung, volume darah, sistem saraf, sistem hormon, sistem metabolik, pikiran atau stres. Di Amerika hampir 70\% masyarakatnya memiliki tekanan darah yang tidak terkontrol. Sejauh ini pemberian obat-obatan, olah raga, diet rendah garam, olah raga secara teratur, ternyata masih belum mampu mengontrol tekanan darah (Udjianti, 2010).

\section{Pengaruh terapi dzikir tasbih pada pasien pre operasi bedah hernioraphy terhadap tekanan darah sistole dan diastole}

Hasil penelitian diketahui bahwa Pvalue $=0,010$, hal ini menunjukkan bahwa ada 
perbedaan yang signifikan terapi dzikir tasbih pada pasien pre operasi bedah hernioraphy terhadap tekanan darah sistole di Ruang Rawat Inap RSUD Kota Semarang. Hasil penelitian diketahui bahwa Pvalue $=0,016$, hal ini menunjukkan bahwa ada perbedaan yang signifikan terapi dzikir tasbih pada pasien pre operasi bedah hernioraphy terhadap tekanan darah diastole di Ruang Rawat Inap RSUD Kota Semarang. Terapi dzikir menyebabkan respon relaksasi yang ditandai dengan penurunan tekanan darah dan denyut jantung. Keadaan ini menimbulkan ketenangan pikiran yang akan memicu pelepasan serotonin, enkephalin, betaendorphins dan zat lainnya ke dalam sirkulasi.

Terapi dzikir selain sebagai terapi komplementer juga dapat digunakan sebagai terapi kesehatan spiritual. Menurut Abdurrochman, Perdana, dan Andhika (2007) sebagai muslim biasa membaca Al-Quran dalam berbagai kesempatan termasuk untuk penyembuhan penyakit. Terapi dzikir dapat mempercepat waktu pemulihan di recovery room pasca anestesi umum, sehingga pemberian terapi dzikir dapat digunakan sebagai terapi komplementer pasca bedah atau anestesi umum.

Keinginan dan harapan terbesar pasien yang akan menjalani operasi adalah agar operasi dapat berjalan lancar dan pasien dapat pulih seperti semula. Maka kebutuhan terbesar adalah kekuatan penyokong, yaitu realitas kesadaran terhadap adanya Tuhan Yang Maha Esa (Krishna, 2001). Dengan terapi dzikir maka kualitas kesadaran seseorang terhadap Tuhan akan meningkat, baik orang tersebut tahu arti Al-Quran atau tidak. Kesadaran ini akan menyebabkan totalitas kepasrahan kepada Allah SWT, dalam keadaan ini otak berada pada gelombang alpha, merupakan gelombang otak pada frekuensi 7-14HZ. Ini merupakan keadaan energi otak yang optimal dan dapat menyingkirkan stres dan menurunkan kecemasan (MacGregor, 2011).

Penelitian Sutrisno (2010) dengan judul Pengaruh Bimbingan Doa dan Dzikir Terhadap Kecemasan Pasien Pre Operasi. Penelitian tersebut dilakukan di RSUD Swadana Pare Kediri. Hasil penelitian tersebut membuktikan ada perbedaan yang signifikan pada kecemasan pasien pre operasi antara pasien yang diberi bimbingan doa dan dzikir dengan yang tidak $(\mathrm{t}=-3,344$ dan $\mathrm{p}=0,002)$.

\section{Kesimpulan}

Tekanan darah sistole sebelum terapi kelompok perlakuan rata-rata $150 \mathrm{mmHg}$. Tekanan darah diastole sebelum terapi kelompok perlakuan rata-rata $88 \mathrm{mmHg}$. Tekanan darah sistole 
sebelum kelompok kontrol rata-rata 151,33 mmHg. Tekanan darah diastole sebelum kelompok kontrol rata-rata 86,67 $\mathrm{mmHg}$. Tekanan darah sistole sesudah terapi kelompok perlakuan ratarata 135,33 mmHg. Tekanan darah diastole sesudah terapi kelompok perlakuan rata-rata 76 mmHg. Tekanan darah sistole sesudah kelompok kontrol rata-rata $144 \mathrm{mmHg}$. Tekanan darah diastole sesudah kelompok kontrol rata-rata $82,67 \mathrm{mmHg}$.

Ada perbedaan tekanan darah sistole pada kelompok perlakuan. Ada perbedaan tekanan darah diastole pada kelompok perlakuan. Ada perbedaan tekanan darah sistole pada kelompok kontrol. Ada perbedaan tekanan darah diastole pada kelompok kontrol. Ada perbedaan yang signifikan terapi dzikir tasbih pada pasien pre operasi bedah hernioraphy terhadap tekanan darah sistole. Ada perbedaan yang signifikan terapi dzikir tasbih pada pasien pre operasi bedah hernioraphy terhadap tekanan darah diastole.

\section{Saran}

Rumah sakit sebaiknya menerapkam terapi non farmakologi seperti terapi dzikir untuk mengatasi peningkatan tekanan darah pada pasien yang akan menjalani operasi agar pasien merasa tenang dan tidak cemas saat akan operasi. Institusi sebaiknya memberikan materi dan praktek terhadap mahasiswa tentang terapi yang dapat menurunkan tekanan darah seperti terapi dzikir, terapi musik atau relaksasi distraksi. Perawat sebaiknya menerapkan dan menganjurkan pasien untuk terapi dzikir sebelum pasien menjalani operasi agar tekanan darah pasien normal.

\section{Daftar Pustaka}

Abdurrochman, A. P \& Andhika, S. (2010). Muratal Al-Qur'an Alternatif Terapi Suara Baru. Jurnal Prosiding Seminar Nasional Sains dan Teknologi-II.

Elkaysi, A. F. (2012). Pengobatan Doa-zikir dan Ruqyah. Jakarta : Mutiara Media.

Devi, D. (2010). Pengaruh terapi musik terhadap respon psikofisiologis pasien yang mengalami caronory angiography di pelayanan jantung Rumah Sakit Umum Cipto Mangungkusuomo. Skripsi tidak dipublikasikan.

Gusmian. (2010). Ruqyah Terapi Religi Sesuai Sunnah Rasulullah SAW. Jakarta : Pustaka Marwa.

Hadi, A. (2010). Seni dan Religiusitas Spiritualitas Islam.

Long, B.C. (2010). Perawatan Medical Bedah. Bandung : Yayasan IAPK Pajajaran. 
Muttaqin, A. (2010). Asuhan Keperawatan Klien dengan Gangguan Sistem Kardiovaskuler dan Hematologi. Jakarta : Penerbit Salemba Medika.

Nafi'ah, Z.R. (2015). Pengaruh pemberian murottal Al-Quran terhadap tekanan darah dan frekuensi denyut jantung pasien pasca operasi dengan anestesi umum di Rumah Sakit Umum Daerah Dr. Moewardi Surakarta. Skripsi tidak dipublikasikan.

Nursalam. (2010). Konsep dan Penerapan Metodologi Penelitian Ilmu Keperawatan. Pedoman Skripsi, Tesis, dan Instrumen Keperawatan. Jakarta : Penerbit Salemba Medika.

Profil Kesehatan Indonesia. (2015). Profil Kesehatan Indonesia. Indonesia : Kementrian Kesehatan Republik Indonesia.

Potter, P \& Perry, A.G. (2010). Fundamental keperawatan, konsep, klinis dan praktek. Jakarta : Penerbit Buku Kedokteran EGC.

Qulsum, A. (2011). Perbedaan tingkat kecemasan pada pasien pre operasi sebelum dan sesudah pemberian Terapi Musik Klasik di RSUD Tugurejo Semarang. Skripsi tidak dipublikasikan.

Rothrock, J.C. (2012). Perencanaan Asuhan Keperawatan Perioperatif. Jakarta : Penerbit Buku Kedokteran EGC.

Sudoyo, A.W. (2010). Buku Ajar Ilmu Penyakit Dalam. Jakarta : FKUI.

Suherly. (2011). Perbedaan tekanan darah pada pasien hipertensi sebelum dan sesudah pemberian terapi musik klasik di RSUD Tugurejo Semarang. Skripsi tidak dipublikasikan.

Udjianti, W.J. (2010). Keperawatan Kardiovaskuler. Jakarta : Penerbit Salemba Medika.

WHO. (2015). World Health Organization. 